\title{
ENVIRONMENTAL CUES: A METHODOLOGY FOR STUDYING MEANING IN BUILT ENVIRONMENT
}

\author{
Vehbi TOSUN \\ İstanbul Kültür University, Turkey \\ v.tosun@iku.edu.tr
}

\begin{abstract}
The interest in culture and built environment relations has received a growing attention during the last decades. The culture and built environment relations are more crucial when changes in both are more rapid and excessive since such changes can severely threaten continuity in the built environment and culture and may have undesirable physical, social and culturel consequences. Environmental cues which communicate meanings at different levels are very helpful in studying culture and built environment relations as well as changes in both them across different areas and over time. Than the task is, how one can study what they communicate, how they communicate, which are the most important ones, how one can analyze those cues and what meanings they communicate to the local and other people. In this paper the theoretical framework as well as the model for analyzing changes in culture and the built environment is established. Research methods and the procedures are discussed in detail and a comprehensive research methodology for analyzing the culture and built environment relations via environmental cues is proposed. The proposed approach can be used for different environments, at different scales as well as in incorporating the values, meanings and lifestyles of the different user groups, in designing the new.
\end{abstract}

Keywords: Built environment, culture, meaning, environmental cues, methodology.

\section{ÇEVRESEL İPUÇLARI: YAPI ÇEVRESININN ANLAMININ İNCELENMESİ İÇIN BİR YÖNTEM}

\section{ÖZ}

Son yıllarda kültür ve yapılandırılmış çevre ilişkilerine artan bir ilginin olduğu görülmektedir. Kültür ve yapılandırılmış çevre ilişkileri, değiş̧imlerin daha hızlı ve aşırı olduğu durumlarda daha da önem kazanır, çünkü bu değişimler yapılandırılmış çevrenin ve kültürün sürekliliğini ciddi bir şekilde tehdit edebilir ve istenmeyen fiziksel, sosyal ve kültürel sonuçlara yol açabilir. Farklı seviyelerde anlamları ifade eden ve ileten çevresel ipuçları, kültür ve yapılandırılmış çevre ilişkilerinin yanı sıra her ikisinde de farklı yerlerdeki ve zaman içindeki değişikliklerin incelenmesinde çok yararlıdır. Bu noktada hedef, çevresel ipuclarının ne ilettiklerini, nasıl ilettiklerini, en önemlilerinin hangileri olduğunu, bu ipuçlarının nasıl analiz edilebileceği, yerel ve diğer gruplar için ne anlama geldiklerini anlamaktır. Bu yazıda teorik bir çerçeve çizilerek, kültür ve yapılandırılmış çevredeki değişimleri analiz edebilmek için bir model oluşturulmuştur. Bu amaçla, araştırma yöntemleri ve prosedürleri ayrıntılı olarak ele alınmış, kültür ve yapılandırılmış çevre ilişkilerinin çevre ipuçlarıyla analiz edilmesi için kapsamlı bir araştırma metodolojisi önerilmiştir. Önerilen yaklaşım, farklı ortamlarda, farklı ölçeklerde uygulanabilirken, farklı kullanıcı gruplarının değerlerinin, anlamlarının ve yaşam tarzlarının, yeni tasarımlarda yansitılmasinda yararlı olacaktır.

Anahtar Kelimeler: Yapı Çevresi, kültür, anlam, çevresel ipucları, yöntem. 


\section{INTRODUCTION}

The reciprocal dynamic relation between culture and built environment and changes in both has been underemphasized or not been given adequate attention by the researchers until very recently. The interest in culture and built envirnment, as indicated by increasing number of publications, conferences as well as with the courses offered both at graduate and undergraduate levels in various universities, has largely been generated by the pioneer work of Rapoport: "House Form and Culture"(1969). Most of his work was based on vernacular environments: environments which constitute by far the majority of all built environments but also have been ignored in architectural theory and history.

Even we may consider vernacular architecture as a specific aspect or kind of built environment today, works of Rapoport (1969), Paul Oliver (1969) and Christopher Alexander (1964) has many imlications for studying different kinds of built environment as well as architectural history more specifically "institutionalized" or high-style" architecture. Regarding high-style architecture, certain characteristics, elements or details have been identified in defining the styles yet a systematic study using environmental cues have not been used immensely. Environmental cues are also important for studying architectural styles since in most cases certain cues such as a gargoyl or an extended dome can play an important role in losing or defining a buildings stylistic identity. Regarding meaning the distincions are only made in general terms such as baroque in Italy expressing the power of church and the baroque in France expressing the power of new aristocracy. On the other hand starting with the late 18th century, particularly in western high style architecture, a mixture of elements from previous historical styles have been used to create as a new and original, ending in eclecticism. The built environment which completely changed with the world-wide modern movement in architecture is even more problematic when one looks the meaning of built environment from man-environment and cultural perspectives.

The image of the built environment is one of the most critical issues today. Hassan Fathy's project is an excellent example for this since he tried to do the all right things yet local people rejected it because for them the right image was modern houses. A research on social meaning in Eastern Black Sea Region has also many implications for why vernacular and traditional house forms were rejected and new concrete houses were preferred although they were rated low in most of functional and aesthetic criteria (Tosun 1998).

\section{THEORETICAL BACKGROUND}

In studying different types of built environments, historical or contemporary landscapes, one can not neglect people since they are built by people, (namely by architects or architecture without architects as Rudofsky points out in his book 1964) and built for people. This makes it necessary to look any city, town, building or interior with an man-environment relations perspective. This is the main difference between architectural design and other design areas which necessitates to include "man" in design process.

If one accepts the above notion, than in studying architecture the characteristics of the people, as individuals and as members of various social groups which affect the way in which built environments are shaped becomes important. In the case of individuals, the first question is about the people's sensory capacities: how individuals perceive it, give it meaning hence choose and use it. These are also affected by membership in a particular group so people must be considered as members of groups with particular values, beliefs and ways of understanding the world. Peoples membership in small groups, families, larger social groups and institutions, subcultures and cultures affects their soles, the ways in which they communicate and so on. These all affect decisions about the built environment and might be also affected by it. The last point makes it essential to know what are the effects of the

Submit Date: 10.01.2019, Acceptance Date: 25.03.2019, DOI NO: 10.7456/10902100/021

Research Article - This article was checked by Turnitin 
environment on human behaviour, mood or well-being. If there are major or certain effects or even minor effects than there is need to study or concern for men environment relations. Yet there is no consensus at theoretical position and there are three theoretical attitudes in general:

1) Environmental Determinism: The physical environment determines human behaviour and choices,

2) Possibilism: Physical environment provides possibilities and constraints within which people make choices based on other mainly cultural criteria

3) Probabilism: The physical environment does in fact provide possibilities for choice and it is not determining, but that some choices are more probable than others in a given setting.

In planning and design environmental determinism has been the traditional view, the belief that changes in the form of cities and buildings can lead to major changes in people's behaviour, increased happiness, social interaction etc. As a reaction to this, the view was put forward that the physical environent and its organization have no effects on people and that is the social, economic and other factors are more important. The current view is that the built environment can be seen as a behaviour setting, a setting for human activities and built environment has important although not determining effects. Only under reduced competence (elderly, children, handicapped, migrants etc.) it may have more inhibiting effects and thus more critical. This reduced competence or environmental docility may be also cultural, so that groups undergoing very rapid change, groups whose culture is marginal and so may be affected critically by inappropriate forms of the built environment.

One important difference between vernacular architecture and high-style architecture is that in the former the model and the meaning that built environment communicates is shared by everyone, thus environmental cues have very high relevance for the people and are used in appropriate ways. Naturally, when the model changes from one building to another with little variations than the model can be understood more quickly. What is lacking today is that we do not have a model with understandable changes but freedom of design with no reference to the existing built environment, culture and architectural history. The result is total chaos, complexity and rag bag in design terms: The lost of image at different scales. On the other hand with such design attitude we lost the identity of space. Whereas in traditional architecture each little area, city or town had certain uniqueness to make it different than the next one. Often this uniqueness was sensitive and in harmony with the physical, social and cultural environment. While they were different from one another they were not chaotic. The reason for that was, they varied from one another in a systematic way enabling one to be aware of transitions: what we lack today in our built environment.

If one accepts the notion that we shape our environment and the environment shapes us than one outcome of rapid changes in built environment is stress which in fact we all feel today. The extensive changes in our built environment with increasing cultural diffusion and enormous commercial ads results in cultural alienation and breakdown. Than the question is how we can modulate, moderate and articulate this fast rate of change and re-establish the model at different scales. The scale of the task may change from city landscape to a room or to a particular architectural detail. Supportive design as advocated by Rapoport (1983) may help in such cases.

When changes are more excessive and rapid than the study of cultural change and built environment becomes even more important and necessary. The outcome is: reduced competence in adaptation process which results in environmental stress, eliminate community identity, sense for community, prevent cooperative and mutual help, disrupt social structure and networks or certain institutions, solidarity, family ties, certain ritual, social, economic activities, cognitive schema etc. These are compounded by the lack of perceived choice and control when changes are rapid, forced and

Submit Date: 10.01.2019, Acceptance Date: 25.03.2019, DOI NO: 10.7456/10902100/021

Research Article - This article was checked by Turnitin 
involuntary and when groups' central values are threatened. In such cases, stress can be modulated by providing appropriate supportive environments. By supporting traditional and/or familiar activities and those elements most important to the cultural system (core elements), supportive environments provide a familiar base and avoid the need to totally restructure cognitive schemata, thus reduce stress. This is also very important at different scales such as cities, towns, neighborhoods and buildings, where we need to restore our cognitive schema related to the image of the built environment.

Another outcome of rapid change and exposition to vast amount of newness is the concept of cultural lag. Changes in material culture often occur more rapidly according to non-material culture and this can also have undesirable consequences. Material culture is anything that can be seen on the landscape such as towns, houses, furniture, musical instruments, etc., while non-material culture is anything that makes up culture and can not be touched like language, religion, folklore, beliefs, traditions, superstitions etc. As Spindler (1977) points out, an object such as a steel axe is far easier to communicate than a concept such as "honor" or "shame" and therefore its acceptance and diffusion is more likely and rapid. Similarly, a new material for the roof of a house or a tractor for a peasant is more communicable than a concept like privacy. Not only a steel axe, a tractor or a new material for roof is more communicable, they are often more compatible with cultural norms and rules. Cohen (1974) in a similar argument also suggests that cultural changes occur more slowly according to technological changes since people resist the necessary accompanying changes in their organizations of social relations and spatial behaviour.

Koh's (1976) similarly suggests that the changes in behavioral culture do not occur as easily as changes in material culture or spirutual culture since behavioral patterns are closely related to customs and norms. Based on Koh's model, Choi's (1986) study of Korean architecture suggests that users' spatial behaviour (behavioral culture) is more traditonal compared to built environment (material culture). We can say that innovations, elements related to material culture are diffused and adopted more easily, rapidly and readily. This result in incongruence between built environmant and users' spatial behavior as well as with other components of culture. This failure of non-material culture to change as rapidly as material culture changes creates cultural lags and dissonance resulting in discord and dissatisfaction in many cases.

Changes in environments are critically related to meaning which provides much of the rationale for the ways in which they are shaped. New materials and forms are to be seen not in terms of comfort, convenience, improvement in livability and the like, but as statements of meaning about "modernity", or "westernization", which is often equated with higher social status and identity. Once they start living in these modern houses, people may encounter certain undesirable, unanticipated consequences and inconvenience. Similarly, Le Corbusier's Pessac housing is a another example for this.

When changes in the built environment are rapid and excessive, they may lead to the destruction of cultures and consequently to the loss of identity (Rapoport 1982b). In the rush to build a better present (which is often associated with the images of western, modern, urban, elites etc.) in many cases we often squander our cultural heritage and identity. When we thoughtlessly obliterate the built environment we also lose our sense of rootedness in time nationally and individually. This in fact is the main point in the tireless and uncompromising crusade of Max Dworax (1916 cited in Rowntree and Conkey 1980) in Austria, who politicized the issues of personal and national identity via the traditional landscapes. His efforts created a public awareness of how and why replacement of traditional landscape by modern buildings can destroy the symbols of cultural continuity and stability as well as individual, family and national identity.

Submit Date: 10.01.2019, Acceptance Date: 25.03.2019, DOI NO: 10.7456/10902100/021

Research Article - This article was checked by Turnitin 
A similar response can also be seen in other cultural groups under acculturative forces where a particular reactive mechanism "defensive structuring" occurs (Siegel 1970, Rapoport 1978). This involves a group concentrating on a few traditional key elements to establish and maintain group identity. Elements of defensive structuring can be food habbits, language, religion, rituals as well as specific settings, neighborhoods or material forms especially extant ones such as the visible form of the cultural landscape or building elements. In many cases groups use environmental cues in establishing and reasserting their identity (Rowntree and Conkey 1980, Rapoport 1982b). Analysis of built environment using environmental cues approach can be also very useful for this purpose.

On the other hand, when people are exposed to many alternatives and when one has to choose between two equally attractive options, one's value judgement of the options can change after the choice has been made. In 1954 Dr. Leon Festinger drafted a version of a theory describing the psychological phenomenon that occurs in these situations. He called it cognitive dissonance: the feeling of psychological discomfort produced by the combined presence of two thoughts that do not follow from one another. Festinger proposed that the greater the discomfort, the greater the desire to reduce the dissonance of the two cognitive elements. Cultural consensus theory (CCT) which emerged from Festinger's earlier work has many implications for linking culture, cognition and environment. It offers a popular information pooling methodology used in social and behavioral sciences. CCT consists of cognitive models designed to determine a consensus truth shared by a group of informants (respondents), and to better understand the cognitive characteristics of the informants.

Environmental cues approach can also be very useful in all these circumstances. The built environment communicates very clearly which many scholars takes as granted yet what it communicates and how it communicates is the concern of this paper. Than the problem is what are the most important environmental cues, how one can analyze those cues and what meanings they communicate to the local and other people.

\section{ENVIRONMENTAL CUES AND MEANING}

People react to environment in terms of the meanings the environments have for them and while doing this they use the environmental cues that environments convey. The meanings are in people not in objects or things. Yet the designers meanings and the users meanings are often different (Rapoport 1982a, Devlin 1990). Man-environment research indicate that designers and users preferences are very different since their schemata vary. While the designers tend to react to environments in perceptual terms (which are their meanings), people react to environment in associational terms. Personalization, changes or additions in the built environment must be conceived in this respect. Obviously, users meanings are more important than architect's or critics' in many cases.

Regarding meaning, Rapoport (1982a) suggests that one has to also make distinction between intended and attributed meaning. Intended meanings originate from direct experiences and relations with the environmet whereas attributed meaning lacks the personal experience and assessment. It is the attributed meanings which we often see as defining choices. Choices that most of the people make but in many cases suffer are based on attributed meanings, since those choices are made based on others intended meaning which have than become an attributed meaning not necessarily having the same intentions, needs or goals. As an example, the intended meaning of a real-estate developer or an architect is often different than the community or one who pays for it. One has to think about the intentions of the architect and if it relates to cultural landscape or communal schema in placing Odakule building at the heart of historical district Beyoğlu in Istanbul. Similarly, within the idea that the traditional Istanbul houses will be satisfactory if only wood were to be replaced by concrete, which is reflected in Eldem's design for upper class housing in Istanbul, one can see such an attitude.

Submit Date: 10.01.2019, Acceptance Date: 25.03.2019, DOI NO: 10.7456/10902100/021

Research Article - This article was checked by Turnitin 
Environmental meaning can be studied; using linguistic models mainly based on semiotics (most common); relying on the study of symbols (art history, high-level meanings, designers meanings); and finally using models based on non-verbal communication that come from antropology psychology and ethology. The latter relating to users' everyday meanings.

Symbolic Approach has been mainly used in historical high-style architecture. The importance of symbols has been recognized and well studied. It has also been used in structuralism and in symbolic antropology. This approach has proved particularly useful mainly in situations where fairly strong and clear schemata are expressed (fixed and shared), through the built environments, whether high style or vernacular. In such cases the cues are clear, consistent and comprehensible. This is more complicated today where symbols are not fixed, shared and change rapidly. In many cases the symbols are created elsewhere and do not belong to the community. Yet, in contemporary situations, the meanings encoded in the built environment tend to be more ordinary and mundane so the symbolic meaning in the built environment is less important and restricted to certain building types. Particularly for understanding users' meanings in everyday environments, symbolic analyses are not useful (Rapoport 1986).

Yet even in analyzing historical high-style architecture, the environmmental cues are usually complicated as well as specific cues are used in various periods that they really do not belong. This is particularly the case at transition periods as well as in buildings which has completed in extended periods or that have additional parts such as Florence Cathedral and St. Peters church at Vatican. As in Villa Farnesina in Rome and Garnier Opera in Paris the exterior and the interior have different cues belonging to different architectural movements. It gets even more harder when one analyze environmental cues of an eclectic building built in the 19th century. The proposed environmental cues approach and methodology can also overcome this problem in such situations. As in environmentbehaviour studies, anthropology and archeology environmental cues can be also very useful in understanding particular architectural movements as well as their meanings and how they are related to the current conditions in the society both using synchronic and diachronic analyses.

Most of the recent studies in architecture on environmental meaning are based on semiotics, the science of signs. Semiotics, as the study of the significance of elements of a structured system can be understood as comprising three major components: syntactics, the study of structure of the system; semantics, that is how signs carry meanings, the property of elements; and pragmatics, which is less used but more important such as which elements function in what ways, how they influence emotions, attitudes, preferences and behaviour. In other words pragmatics is based on the relation of signs to the behavioral responses of people that is their effects and how these elements or cues interpreted.

The main source for semiotics comes from Saussure's (1916) seminal work "Course in General Linguistics". His division of the signs into two components, the signifier (sounds or marks on paper) and the signified (concepts or ideas), was transformed so that the building or its former details (signifier) stand for certain meanings and concepts which are signified (Broadbent, Bunt and Jencks 1980, Groat 1981, Krampen 1979, Lindsey, Buchan and Duncan 1988). First the main concern was on the signified, later the emphasis was on both components of the sign -the signifier as well as the signified.

The studies on meaning within the semiotic tradition also made several contributions to the study of meaning. For example, one aspect of Krampen's studies was his use of sorting task as a research methodology for identifying building types. His procedure was to ask subjects to sort pictures of buildings based on cues into categories of building types. Bonta's (1979) ananlyses within the semiotic traditon are also worth mentioning. According to Bonta meaning in built environment can be achieved

Submit Date: 10.01.2019, Acceptance Date: 25.03.2019, DOI NO: 10.7456/10902100/021

Research Article - This article was checked by Turnitin 
through the analysis of descriptive texts of critics and other writers. Rather than using architectural criticism as a source for empirical research, he used it as a source of what he called text analysis. He applied text analysis to the study of particular periods or styles as well as to the study of single buildings over aperiod of time in order to identify the changes in meanings. One important issue regarding semiologically oriented analyses is that they are almost exclusively based on the formal details of building facades.

In comparing these approaches Rapoport $(1982,1988)$ suggests that nonverbal communication approach is the most useful one since it is based on relatively simple, direct, immediate methods, involving observation, recording and interpretation, which can be applied easily in the field. He argues that built environments lack the clear-cut lexicons with indexial relationships to referents that language possesses and the communication channel in language is based on auditory sense whereas the communication channel for built environment is mainly visual although other sensory cues may also be involved. The built environment provides cues but does not do so verbally but mostly visually hence it represents a form of nonverbal communication. In fact even in linguistics importance of nonverbal communication (such as tone of voice, facial expressions, physical position, body movements, gestures etc.) has recently been recognized and considered important for clarifying spoken language. That is, instead of studying the internal relationships and structures of alanguage as in traditional linguistics, they examine language in the "context" of actual communicative events based on the notion that the nature of any given speech may vary depending on the context. The importance of context is very important noticing the differences and studying the meaning of built environment and this necessities the knowledge and familiarity with the cultural context (nationalism, struggle for ethnic or social identity, lifestyles, worldviews etc.) since it helps in reading the cues and prevents one from making misinterpretations.

From a pragmatic view in a heavly forested area a clearing becomes the cue of humanized space whereas in a treeless plain a tree or a group of trees is the cue for humanized space. The reversal between the relative meaning of town (good) and forest (scary, full of with wild animals, dark, bad etc.) so common in early colonized America and the present meaning of forest (good) and town/city (bad, urban crimes, dangerous, air pollution, traffic etc.) have to do with changing values, which also indicates that they are also interpreted in terms of their context. In a white washed Greek island the church is identified by use of domes and size while in in a town of mud brick in the Peruvian Altiplano the use of color whitewash reinforced by an arched door and a small bell tower marks the church. In Taos pueblo a a freestanding building, surrounded by a wall and gateway with a pitched roof contrasting with clustered houses with flat roofs identify the church. In south Italy and in many parts of Central Anatolia use of stone in a church or mosque makes this distinction. In many cases the cue is also reinforced by multi cues such as size, location, domes, color, materials, classical doorways or columns etc. These also make the context important. In a low rise neighborhood a tall building becomes a landmark whereas in a city where high rise blocks are abundant a low rise community becomes a landmark or district. The reading of meaning requires context as well as in many cases knowledge. The reason why traditional forms and materials are rated positevely in western world and concrete, galvanized iron, modern forms are preferred eagerly in developing world can be understood by contextual meaning.

According to Rapoport (1995), built enviroments communicate several distinct types or level of meaning through environmental cues. These are 'high level meanings' which are related to cosmologies, cultural schemata, world views, philosophical systems, the sacred etc.; 'middle-level meanings' which are related to identity, status, wealth, power, prestige, i.e. the latent meaning rather than instrumental functions, and 'lower-level' everyday and instrumental meanings that are related

Submit Date: 10.01.2019, Acceptance Date: 25.03.2019, DOI NO: 10.7456/10902100/021

Research Article - This article was checked by Turnitin 
identifying the uses for settings, expected behaviour, privacy, territoriality, seating arrangements etc., thus enabling users to behave and act appropriately and predictably.

The lower-level meanings are present in any built environment and it is the most evident. The higher level meanings are more important in traditional settlements, historical landscapes, ritual buildings etc. and it has been mainly emphasized in architectural theory and history as well as in anthropology and archeology. In present day environments, middle level meanings have become more important due to the scale, complexity and heterogeneity of the society. When people do not know each other and when social mobility in a socity increases, communication of identity and status becomes more important. In most cases, higher level meanings are often unknown or of little concern to most users. The studies by Duncan and Duncan (1980), Gauvain, Altman and Fahim (1984), Amaturo, Costagliola and Ragona (1987), Sadalla, Vershure and Burroughs (1987), Rapoport (1988) illustrate the growing interest in middle level meanings. Actually, identity and social status has become one of the goals of architecture besides form and function debates. One has to consider that, meaning is a central mechanism linking people and the built environment, influencing perception, making it selective through the affective response to sublimal cues, influencing cognitive schemata and memory thus dominating evaluation, prefence and choice, so that even aesthetics can be an aspect of meaning (Tosun1999).

Regarding meaning, Rapoport (1982a) suggests that one has to also make distinction between intended and attributed meaning. Intended meanings originate from direct experiences and relations with the environmet whereas attributed meaning lacks the personal experience and assessment. It is the attributed meanings which we often see as defining choices. Choices that most of the people make but in many cases suffer are based on attributed meanings, since those choices are made based on others intended meaning which have than become an attributed meaning not necessarily having the same intentions, needs or goals. As an example, the intended meaning of a real-estate developer or an architect is often different than the community or one who pays for it. One has to think about the intentions of the architect and if it relates to cultural landscape or communal schema in placing Odakule building at the heart of historical district Beyoğlu in Istanbul. Similarly, within the idea that the traditional Istanbul houses will be satisfactory if only wood were to be replaced by concrete, which is reflected in Eldem's design for upper class housing in Istanbul, one can see such an attitude.

What people want is an important question but why people want these is more important. At consumers level, instrumental function and latent function is often different. The latent meaning can be more important in many cases. As designers we can not control certain quality components such as cleanness or maintenance, certain urban services, garbage collection, electricity and water problems, proximity to services, perceived crime levels and safety. Yet there are many ways to change the environmental quality of an area with new well-designed projects and bringing higher status elements to an area (downtowns, projects in certain parts of Istanbul with increasing the value of land etc.). Designers usually control appearance although preferences can be highly variable. Appearance is also linked to associational variables (status, income etc.). This can also change from one society to another as well as in a society. In latin America grid plans are considered better in neighborhoods where as in US curved and non-linear planning with culde sac is preferred. Also an apartment on a crowded street is preferred in Turkey whereas in US or North Europe a silent street is preferred. In Eastern Black Sea while viewing the land and locating house on the slopes for that purpose was a must, now the houses are located along the roads which are usually in the valley although in every rainy season some of them are sweeped by the floods. In urban areas environmental quality preference can change according to knowledge and mental maps (Istanbul Europe and Asia side preferences), view (river,lake,sea, valley), lifestyles (culture), according to their geodemographic background (Eastern Black Sea people in Beykoz and Saryer), activities (sportive, cultural, outdoor etc), social contact and

Submit Date: 10.01.2019, Acceptance Date: 25.03.2019, DOI NO: 10.7456/10902100/021

Research Article - This article was checked by Turnitin 
interaction (particularly for young working couples and single people), child density, large and small trees, availability for maintenance (elderly) etc.

Regarding man environment relations, the environmental cues also communicate meaning and indicate people how to act. The built environment act as a mnemonic reminding people expected behaviour. In this respect the contemporary environments provide less information to make people make up their minds. This is partly due to the decrease in shared knowledge as well as to the cultural lag that results from excessive changes in built environment. The difference between the intended meaning of an architect or real-estate developer and the community also makes this process vague.

Environmental cues are also very helpful in analyzing and assessment of environmental quality. The assessment of quality also is not universal and different groups can have different environmetal quality profiles. Profile diagram is basically based on people's evaluations of the environmental attributes (which in most cases are the cues that are selected by people) which can be analyzed using a negativepositive diagram (Rapoport 1990). Similarly, lifestyles can also be represented as profile. Lifestyle can be defined as the result of choices about how to allocate resources and closely linked to consumption patterns like food, drink, clothing, transportation, media etc. as well as to recreation and leisure activity systems hence to location, neighbourhood and more importantly to the choices for housing. In fact lifestyle matches environmental quality well since both profiles emerge from what people choose. They are the link between the choices and the specifics of the built environment. As an activity design itself is the result of choices among alternatives. The style itself whether of environment or life, is the result of systematic choices among alternatives. In this connection environmental cues which includes embodied images are very important for housing, office space advertisements since they help in selling dreams.

\section{A METHODOLOGY FOR STUDYING BUILT ENVIRONMENT VIA ENVIRONMENTAL CUES}

The basic methodology for studying built environments involves looking directly to the built environment and its elements, attributes, observing the cues present in the designated research context and identifying how they are interpreted by the members of the society living in that area. Therefore the research methods include both observations of the built environment and/or analysis of the recurring properties as well as interviews with the inhabitants and the various groups living in that area

Concerning the relationship between built environment and culture, more specifically the meaning in built environment, one has to consider that these not only change from one place to another but also change over time. Hence the research methodology for studying environmental cues and their meaning can be based on synchronic analysis across various built environments and cultures (cross-cultural comparatively and non-chronological), diachronic analysis (chronological usually based on one specific place and culture over time) as well as both at the same time.

The unit of the study can variably be a city or a town landscape, a neighborhood, an individual building, a specific space or an architectural detail such as a door or window. Than the important task is to find out which cues are recurring thus important to that particular time or over time in a given setting and/or across different locality. Those will also undermine the choices of that particular time and setting. This on the other hand can enable one to identify the images and other elements of meaning, discover priorities in preferences and the elements which comprise environmental quality for the inhabitants (Rapoport 1990).

Regarding environmental cues, there have been variable approaches starting with just classification systems such as classifying window and door shapes and details, roof forms, and the like as well as

Submit Date: 10.01.2019, Acceptance Date: 25.03.2019, DOI NO: 10.7456/10902100/021

Research Article - This article was checked by Turnitin 
analythical approaches where one try to deal with the transformations of forms using structuralist and transformational approaches.

Schulz (1988) uses the word "component" as the smallest unit of architectural form. He suggested that the components that made up the architectural form can be categorized in mass, space and facade categories and can be analyzed by processes, relationships, organizations and ordering principles which constitute the form composition components. Processes can be branched as whole (no process), addition, subtraction, deformation, combined processes; relationships can be branched as unique (no relationship), intersecting, adjacent, linking and combined relationships; organizations can be branched as nodal, clustered, linear (one-way or two-way), gridiron and combined organizations; and ordering principles can be branched as repetition, hierarchy, alteration, harmony, gradation, contrast, dominance, unity, balance and combined ordering principles (Krier 1988, Gunce, Erturk and Erturk 2005).

As already discussed environmental quality profile can be adapted in handling diverse cues that environments communicate in understanding consistency in meanings for a group, sub-culture or culture. It enables one to visualize and represent graphically which cues are more important as well as how the cues are evaluated since it allows one to describe what is liked and chosen as well as disliked and rejected. In design it can have many implications why particular cues in built environment are chosen, why, and have positive social meaning at a particular society or a group at a given time. One has to also look at:

1) Nature of components. One may want to be close to mosque or school or not),

2) Ranking of components: People rank house, garden, neighborhoods. Components can be physical (perceptual) as well as social (symbolic, temporal like sound, socio-cultural),

3) Importance: the magnitude of components how important they are. For squatter settlements tenure, safety, water, electricity is more important so the ranking may be different,

4) Push and Pulls: Negative and positive like trees, activities, adoption, neighbors, school quality, etc.

The cues for interpreting environmental meaning can be three types (Rapoport 1982a): fixed, semifixed and non-fixed elements. Fixed-feature elements are those which change rarely, slowly or not at all such as buildings, plazas, streets at urban scale and walls, floors, windows, doors at building scale. Spatial organization of these elements, their size, proportions, forms, arrangement, location and so on communicate meaning. Semi-fixed elements can be changed easily and quickly such as furniture, curtains, shutters, decorations, fences, plants, lawn decorations, personalizations, color and so on. Semi-fixed elements are particularly important in studying meaning since they tend to be more under the control of users and ithey communicate more than fixed elements. For establishing and expressing meaning, group identity, status and the like, semi-fixed elements are very important particularly since most of us move to a ready-made environment and can not change the fixed architectural characteristics.

Apart from fixed and semi-fixed features in encoding and decoding built environment, it is also necessary to consider non-fixed elements. Homogeneity or heterogeneity of the area, the mobility of the respective population, their length of residence, activity systems as well as groups preferences, choices and lifestyle profiles are important for understanding the meaning in built environment. The recurring characteristics of the visual environment has to be further investigated based on what people think about them. Than the first task becomes finding the recurring characteristics of the built environment. 
The nature of environmenal cues, may vary by the type of data and the scale of the measurement. For instance, if the cue is size and height the nature of data can be continuous and in this case the scale of measurement can be interval. There can be also other cues which do not exhibit such range and are discrete such as the color used. There may be also cues which vary discretely but where the distinctions are rather arbitrarily defined, depending upon who is interpreting the situation, such as poor or high maintenance. The degree of criteriality can be different from one cue to another as well as different from one subject to another. The degree of criteriality of a cue not only depends on its value or saliency but also on the content of the environmental display since certain cues may reinforce or override other conflicting cues. In this connection uniqueness and contrast become very important for the analysis of cues and interpreting the meaning of built environment.

In order to make correct inferences, strong noticable differences and adequate redundancy is necessary. When environmental cues add up and reinforce one another, the indications and the messages can be quite clear and one can make reliable inferences. Consistent and repeated use of certain cues can also bring further clarity to the meaning. Due to the ambiguity and uncertainty of environmental cues their redundancy must be high.

Assumptions of reality, the associated meanings and the conflicts about them can be understood using the methodology proposed by cultural consensus theory. While measuring distributed knowledge, values and meanings in a given society one can explain shared human decison-making process and enlighten which environmental cues are the most important for them (Gawronski and Brannon, 2019) The cultural consensus model is a formal model of the process for asking and answering questions and is limited to categorical response data. The proposed model includes a set of analytic procedures enabling one to obtain which knowledge, meanings and values are shared, the correspondance between the answers of respondents and its correlation to certain cues existence or non-existence, existence or non-existence of a single knowledge system in a group, and the extend of consensus on knowledge and meaning system. The repetition of environmental cues and the consensus on meanings can increase the redundancy.

In studying meaning in built environment often an extensive recording based on visual evaluation may be necessary for the data collection. One can adopt Brunskill's method, which was constructed on observations carried out on English vernacular architecture. His methodology helps to collect data quickly in the field and by reducing the subjective elements as much as possible makes it easy to compare the material between different parts of the country (Brunskill 1974). A design matrix based on environmental cues can be produced to do the recording morphologically after a pilot study on characteristics of the environment for the aimed study. This is basically a visual mapping of alternate ways of achieving design solutions, typologies etc. The design matrix includes parameters (what the object is or have) which are listed vertically and the corresponding characteristics or typologies which are listed horizontally. The basic parameters for quantitative comparisions can be the environmental cues which can vary from settlement pattern, massing, landscaping, spatial organization, indications of public versus private, roof shape, materials, color, proportions, sizing, doors, windows, fenestration, ornaments, furnishings, maintanence etc. This method can also be applied to advertisements on media, books, documentary investigations, or various built environments whether traditional or contemporary.

Quantification of the data through the related parameters for the basis of comparisions acts as a filter. This not only makes the data collection faster but also makes the analysis and evaluations easier. In analyzing by rows, where each row is evaluated separately from each other in terms of the basis for comparision, the recurring characteristics gives the optimum for the complete chart. Such recurring characteristics also gives the core elements and the most important cues for that specific built environment. Analyzing by columns is more complex, since it implies analysis of all possible

Submit Date: 10.01.2019, Acceptance Date: 25.03.2019, DOI NO: 10.7456/10902100/021

Research Article - This article was checked by Turnitin 
combinations and permutations (Sanoff 1977). A morphologic path analysis can be used for this purpose. Once the recurring important environmental cues are found than the next step is interviews which can be done in various ways.

Unstructured interviews with the users can be very helpful when one conducts a research in an area which he or she is not familier with or when one seeks for the meaning of the environment for the inhabitants. This can reduce misinterpretations as well as researchers imposing their understandings and knowledge on related issues. The main objectives for conducting the unstructured interviews are: to gather information about the inhabitants (household, identity, occupation, education, status etc.); where and how particular activities take place as well as which activities and in what ways occur in particular settings; what users think and feel about specific spaces, buildings, features, elements (such as how they evaluate their house as well as others' houses or neighborhoouds, which features and elements are important, what makes them important or special etc.); to gather information about specific settings and social relations in that particular environment. These informal interviews can also provide information about which elements and aspects of the built environment (at different scales) are important and what these cues mean to the people which then can be systematically explored during the structured interviews.

Free responsive environmental walk tours are important for the analysis of meaning in built environment since people often remember environmental cues when they actually see them. Naturally this necessitates using strategic informant sampling which in most cases using more educated and elderly inhabitants who can reconstruct the past, identify the changes in meaning of particular forms, buildings, elements over time. A real-estate agent can be a good alternative in researching the current trends. Free response environmental walk tour is useful since the real environment can help in reminding people of their memories as well as can make it possible to check the informations gathered during unstructured interviews, or prelimanary analysis of environmental cues by the researcher. For controlling the data accuracy information gathered from one informant must be checked against that another.

Questionaries whether structured or unstructured can be held after these two steps. Yet for the analysis of the meaning in built environment it is better to do photo interviews before going in further research and analysis. Photo interviews are very useful in understanding the meanings of the various built environments for the local people; to identify which elements are critical and express important meanings; to discover what people think about certain aspects of the built environment and what they represent to them; to identify which elements or features preferred, desired and evaluated as positive or negative by the people and why; to discover which features or elements of the built environment convey information about personal identity, status and community identity. People's inferences from photographs can provide the important and critical environmental cues (or criterial attributes) and what they mean for the local people. As already discussed, such cues and their meanings are very important and have to be considered in designing the new or in proposals for preserving the traditional environments.

Selecting photography as an environmental display media for the structured interviews is very crucial. First, the use of photography as an environmental media is the closest that we can get to the real environment at display and photographs are able to stir up the hidden meanings. It has already been proven as useful and successful for interpreting environment and encoding meaning (Royse 1969, Bunster 1977, Lindsey, Buchan and Duncan 1988, Sadalla, Vershure and Burroughs 1987, Bone 2013, Chow et al. 2014,). Second, while there is a high degree of verisimilitude between the real environment and its photographic surrogate, in a photograph one can control to a large extend the number of stimuli presented at one time to a subject. A photograph can be a close-up detail including

Submit Date: 10.01.2019, Acceptance Date: 25.03.2019, DOI NO: 10.7456/10902100/021

Research Article - This article was checked by Turnitin 
only a single cue such as a door knocker or it can be so complex as a panorama of a village with multitude of cues. Such a control by the researcher in environmental display makes it easy to trace any given response to a stimulus or cluster of stimuli. This is not possible for example in direct and free exploration of the real environment. Third, photo-interviews can be conducted easily anywhere, in the field, in the house or in a coffee-bar. Forth, photographs can be sorted into categories (free- sorting task or structured sorting task) or they can be ranked according to certain criteria by the researcher and the subjects easily for the analyses and the evaluations. Finally, an important positive aspect about photo-interview sessions is that informants usually enjoy pictures and are often eager to continue responding for an extended interview time.

An alternative for photography today is the use of rendering or photo-retouching. This is even a more important technique since one can control as well as add certain environmental cues for the aim of the research. With the developments in rendering and re-touching techniques one can easily create the wanted photorealistic environments for studying the meaning in environment. Just by adding or subtracting certain cues on the images produced, one can easily understand, preferences, values and what meanings that these cues communicate.

Concerning the analysis of photo/rendering-interviews various analysis can be made based on the evaluations. Osgood's (1957) Semantic Differential is widely used to measure the connotative meaning of cultural objects. In relation to sorting tasks and rating scales correlational analysis can be made (such as chi-square test to see relationship between various constructs). One can obtain ordinal, nominal or interval data easily through these structured interviews and make different quantitative analysis. For the ordinal and nominal data non-parametric analysis and matrices can be used.

In the past, architectural models has also been used widely to understand how people interpret and evaluate the built environment, which cues or attributes are more important, acceptable etc. particularly at housing scale and interiors (Stea 1982). Although environmental modelling is useful in some cases since they do not represent the real environment fully in every details such as color and materials, it is not recommended to use this technique particularly in searching for meaning using environmental cues. Retouched drawings have also the same disadvantages. Moreover, both techniques can mostly be understood by designers, not the others. People having no design education are not familiar with them. Yet the photographs and the realistic renderings are what they see in real environment thus more familiar with them.

In manipulating the meaning of built environment through environmental cues, there are two options. One is to take few cues and via doctored photographs or renderings place them in a wide range of environmental contexts. This can give one an understanding of the relationship between a given cue and a range of differing environmental contexts. Such an approach means limiting the cues tested to two or three since each cue has to be tested in various contexts. The other option is to take a large number of cues and test them in one or few environmental contexts.

Retouched photographs and renderings can be very useful in making certain environments such as historical, vernacular or modern, more acceptable to the people by changing few important environmental cues -similar to the suggestions in the US for making townhouses and condominiums more acceptible (Rapoport 1982b). By removing one or two negative environmental cues and adding one or two important positive cues one may change the image (sum of cues having positive or negative meaning for the people and which also identify and tell us about the area and the people) of the built environment. This can also increase the acceptance and desirability for the people. This is particularly important when we want to change the meaning of the built environment from low status to high status. This method is also useful when a change in environmental cues does not change the

Submit Date: 10.01.2019, Acceptance Date: 25.03.2019, DOI NO: 10.7456/10902100/021

Research Article - This article was checked by Turnitin 
ratings. This will clearly indicate that the cue used in retouched phorographs or renderings is not very important.

\section{Conclusion}

Environmental cues can sharpen and refine our understanding of the interactions between people and environment and elicits core and emotive knowledge and values about the environment and insights on meanings as well as shifts in meanings over time. Today the environmental cues approach and the methodology advocated for this purpose is even more important in understanding, which elements seem to be adopted eagerly and used by real-estate developers or in self-built projects, which cues are preferred and looked by customers and what meanings these cues communicate etc. The impact of media and the advertisements is also very critical in this respect: what do the television programs show, what do newspapers and magazines show, what these pictures and films indicate or advocate. By analyzing the most repetitive elements found in various media types, one can than understand which cues are more important and form the current trends in architectural design.

Regarding new design, this approach can make the design process more successful by making the meanings transparent and eliminating the disadvantages of the black-box approach regarding meaning in built environment. Particularly the developments in computer technology and the realistic renderings can help researchers as well as architects and real-estate developers in designing the new with the preferred, more acceptable design alternatives. This is particularly important also in interior architecture since it is even more easy to control each cue much easier in virtual world yet fully realistic. In fact in interior architecture, the approach proposed in this paper is utilized to a degree by many firms in kitchen and bath room renovations business, in finding users preferences and choices. At this point we still do not see such an attitude in the realm of architecture. The buildings that architects design today are still based on architects cognitive schema, their interpretations of the ideas, values and knowledge.

\section{REFERENCES}

Alexander, C. (1964). Notes on the Synthesis of Form, Cambridge, Massachusetts: Harvard University Press.

Amaturo, E., Costagliola, S. and Ragone, G. (1987), Furnishings and Status Attributes, Environment and Behaviour, Beverly Hills: Sage Publications, 9, 2, p.228-249.

Bone, Z. (2013). Looking Through, Looking At and Looking Behind: Using Photos in Research Inference, In I. Romos and A. Mesquita (eds.), Proceedings of the 12th European Conference on Research Methodology for Business and Management Studies, UK: Academic Conferences and Publishing International Limited, p. 48-57.

Bonta, J.P. (1979). Architecture and its Interpretation, New York: Rizzoli.

Broadbent, G., Bunt, R. and Jencks, C. (1980). Sign, Symbols and Architecture, New York: Wiley.

Bunster, B. X. (1977). Talking Pictures: Field Method and Visual Mode, 3, 1, p.278-293.

Brunskill, R. W. (1974). Illustrated Handbook of Vernacular Architecture, London: Faber and Faber. Choi, J. (1986). An Exploratory study of the conceptualization of architectural tradition of Koreans' spatial behaviour. In J. Winemann, R. Barnes and C. Zimring (eds.), The Costs of Not Knowing, Atlanta: EDRA, p.31-40.

Cohen, Y. A. (1974). Culture as Adaptation, In Y.A.Cohen (ed.), Man in Adaptation: The Cultural Present, Chicago: Aldine.

Chow, C. K., Corsi, D.J., Lock, K. and Madhavan, M. (2014). A Novel Method to Evaluate the Community Built Environment Using Photographs, PLoS ONE, 9, 11, p.1-10.

Devlin, K. (1990). An Examination of Architectural Interpretation: Architects versus Non-Architects, Journal of Architectural and Planning Research, 7, 3, p.235-244.

Submit Date: 10.01.2019, Acceptance Date: 25.03.2019, DOI NO: 10.7456/10902100/021

Research Article - This article was checked by Turnitin 
The Turkish Online Journal of Design, Art and Communication - TOJDAC

ISSN: 2146-5193, April 2019 Volume 9 Issue 2, p. 318-333

Duncan, J.S. and Duncan, N.G. (1980). Residential Landscapes and Social Worlds: A case study in Hyderabad, Andhra Pradesh, In D.E. Sopher (ed.), An Exploration of India: Geographical erspectives on Society and Culture, Ithaca: Cornell University Press.

Gauvain, M., Altman, I. and Fahim, H. (1984), Homes and Social Change: A Case Study of the Impact of Resettlement, In R.J. Gergen and M.M. Gergen (eds.), Historical Social Pschology, Lawrance Erlbaum, New Jersey: Hillsdale, p.211-235.

Gawronski, B. and Brannon, S.M. (2019). "What is Cognitive Consistency and Why Does It Matter, Cognitive Dissonance", In Eddie Harmon-Jones and Judson Mills (eds.), Washington DC, American Psychological Association.

Groat, L. (1981). Meaning in Architecture: New Directions and Sources, Journal of Environmental Psychology, 1, 3, p.73-85.

Gunce, K., Erturk, Z. and Erturk, S. (2005). "Visual Interpretation of Architectural Form”, BUHU 5th International Postgraduate Research Conference in the Built and Human Environment, The University of Salford, UK, pp: 385-392.

Koh, Y. (1976). Traditionalism and De-traditionalism, In S.Y.Chun (ed.), Korean Society, Seoul: International Cultural Foundadtions, p. 129-146.

Krampen, M. (1979). Meaning in the Urban Environment, London: Pion Limited.

Krier, R. (1988). Architectural Composition, Ney York: Rizzoli.

Lindsey, S., Buchan, R. and Duncan, J.S. (1988). The Residential Landscape as a System of Communication: A Semiotic Approach, In M. Herzfeld and L. Melazzo (eds.), Semiotic Theory and Practice, Berlin: De Gruyter, 1, pp.591-600.

Oliver, P. (1969). Shelter and Society. London: Barrie and Jenkins Ltd.

Osgood, C., Suci, G. and Tannenbaum, P. (1957). The Measurement of Meaning, Urbana: University of Illinois Press.

Rapoport, A. (1969). House Form and Culture, Engelwood Cliffs, New Jersey: Prentice Hall.

Rapoport, A. (1977). Human Aspects of Urban Form, Oxford: Pergamon.

Rapoport, A. (1978). Culture and Subjective Effects of Stress, Urban Ecology, 3, p.241-261.

Rapoport, A. (1982a). The Meaning of the Built Environment, Beverly Hills, CA: Sage Publications.

Rapoport, A. (1982b). "Identity and Environment: A cross-cultural perspective", In J.S. Duncan (ed.), Housing and Identity: Cross-Cultural Perspectives, N.Y.: Holmes and Meier Publishers.

Rapoport, A. (1983). "Development, culture change and supportive design", Habitat International 7 (5/6), pp. 249-268.

Rapoport, A. (1986). Culture and Built Form -A Reconsideration, In D.G. Saile (ed.) Architecture in Cultural Change:: Essays in Built Form and Culture Research, The University of Kansas, p.157-175.

Rapoport, A. (1988). "Levels of Meaning in the built environment", In F. Poyatos (ed.) Cross-Cultural Perspectives in Nonverbal Communication, Toronto: C.J. Hogrefe, pp.317-336.

Rapoport, A. (1990). "Environmental Quality and Environmental Quality Profiles", in N. Wilkinson (ed.), Quality in the Built Environment, Newcastle upon Tyne, Urban International Press.

Rapoport, A. (1995). Thirty Three Papers in environment-behaviour research, New Castle upon Tyne, Urban International Press.

Rapoport, A. (2005). Culture, Architecture and Design, Chicago: Locke Science Pub. Com.

Rowntree, L.B., and Conkey, M.W. (1980). Symbolism and the Cultural Landscape, Annals of the Association of American Geographers, 70, 4, p. 459-474.

Royse, D.C. (1969). Social Inferences via Environmental Cues, Unpublished doctoral dissertation, MIT, Massachusetts.

Rudofsky, B. (1964). Architecture without Architects, London: Academy Editions.

Saussure, F. (1916). Course in General Linguistics, New York: Mc Graw Hill (1966).

Sadalla, E.K., Vershure, B. and Burroughs, J. (1987), Identity Symbolism in Housing, Environment and Behaviour, Beverly Hills: Sage Publications, 19, 5, 569-587.

Submit Date: 10.01.2019, Acceptance Date: 25.03.2019, DOI NO: 10.7456/10902100/021

Research Article - This article was checked by Turnitin 
Sanoff, H. (1977). Methods of Architectural Programming, Pennsylvania: Dowden, Hutchinson and Ross Inc.

Schulz, C. N. (1988). Architecture: Meaning and Place, Selected Essays, New York: Electa/Rizzoli. Siegel, B.J. (1970). Defensive Structuring and Environmental Stress, American Journal of Sociology, 76, p.11-32.

Spindler, L.S. (1977). Culture Change and Modernization, New York: Holt, Rinehartand Winston. Stea, D. (1982). Cross-cultural environmental modelling. In A. Lutkus and J. Baird, (eds.), Mind, Child, Architecture, Hanover, New Hampshire: University Press of New England.

Tosun. V. (1998). Biçim Anlamı İzler: Doğu Karadeniz Bölgesinin Kırsal Alanlarındaki Yöresel Ev ve Yerleşme Biçimlerinin Değişiminin Analizi içim Kuram ve Yöntem, Unpublished doctoral dissertation, K.T.Ü., Trabzon. 